\title{
Educação Permanente em Saúde: desafio ambicioso e necessário
}

\author{
Permanent Education in the Healthcare field: an ambitious and \\ necessary challenge
}

PALAVRAS-CHAVE: Educação em saúde; educação continuada.

KEYWORDS: Health education; continuing education.

Ricardo Burg Ceccim*

PALABRAS CLAVE: Educación en salud; educación continua.

\author{
${ }^{2}$ Faço a escolha pela \\ designação Educação \\ Permanente em Saúde e não \\ apenas Educação Permanente \\ porque, como vertente \\ pedagógica, esta formulação \\ ganhou o estatuto de política \\ pública apenas na área da \\ saúde. Este estatuto se deveu \\ à difusão, pela Organização \\ Pan-Americana da Saúde, da \\ proposta de Educação \\ Permanente do Pessoal de \\ Saúde para alcançar o \\ desenvolvimento dos sistemas \\ de saúde na região com \\ reconhecimento de que os \\ serviços de saúde são \\ organizações complexas em que \\ somente a aprendizagem \\ significativa será capaz da \\ adesão dos trabalhadores aos \\ processos de mudança no \\ cotidiano. Ver, por exemplo, \\ Maria Alice Roschke, Maria \\ Cristina Davini e Jorge Haddad \\ (Roschke et al., 1994), Maria \\ Alice Roschke e Pedro Brito \\ (Roschke \& Brito, 2002) ou \\ Mário Rovere (Rovere, 1996).
}

\section{Introdução}

Assumo neste texto um caráter autoral, menos me importando com a revisão da literatura que com o destaque ao desafio de reconhecer no setor da saúde a exigência éticopolítica de um processo educativo incorporado ao cotidiano da produção setorial. Pretendo que o texto cumpra a função de estabelecer um debate, cujas sugestões/ induções de pensamento - ou o despertar de pensamento - localizem mais o problema da necessidade da educação na saúde que os delineamentos pedagógicos da vertente que se pode identificar como Educação Permanente.

A identificação Educação Permanente em Saúde ${ }^{2}$ está carregando, então, a definição pedagógica para o processo educativo que coloca o cotidiano do trabalho - ou da formação - em saúde em análise, que se permeabiliza pelas relações concretas que operam realidades e que possibilita construir espaços coletivos para a reflexão e avaliação de sentido dos atos produzidos no cotidiano. A Educação Permanente em Saúde, ao mesmo tempo em que disputa pela atualização cotidiana das práticas segundo os mais recentes aportes teóricos, metodológicos, científicos e tecnológicos disponíveis, insere-se em uma necessária construção de relações e processos que vão do interior das equipes em atuação conjunta, - implicando seus agentes -, às práticas organizacionais, - implicando a instituição e/ou o setor da saúde -, e às práticas interinstitucionias e/ou intersetoriais, - implicando as políticas nas quais se inscrevem os atos de saúde.

\footnotetext{
1 Professor, Programa de Pós-Graduação em Educação, Grupo Temático de Educação em Saúde, Universidade Federal do Rio Grande do Sul; Departamento de Gestão da Educação na Saúde, Ministério da Saúde. <ceccim@edu.ufrgs.br>; <ceccim@saude.gov.br>
} 
A Educação Permanente em Saúde pode corresponder à Educação em Serviço, quando esta coloca a pertinência dos conteúdos, instrumentos e recursos para a formação técnica submetidos a um projeto de mudanças institucionais ou de mudança da orientação política das ações prestadas em dado tempo e lugar. Pode corresponder à Educação Continuada, quando esta pertence à construção objetiva de quadros institucionais e à investidura de carreiras por serviço em tempo e lugar específicos. Pode, também, corresponder à Educação Formal de Profissionais, quando esta se apresenta amplamente porosa às multiplicidades da realidade de vivências profissionais e colocase em aliança de projetos integrados entre o setor/mundo do trabalho e o setor/mundo do ensino.

Para muitos educadores, a Educação Permanente em Saúde configura um desdobramento da Educação Popular ou da Educação de Jovens e Adultos, perfilando-se pelos princípios e/ou diretrizes desencadeados por Paulo Freire desde Educação e Conscientização/Educação como Prática da Liberdade/Educação e Mudança, passando pela Pedagogia do Oprimido, Pedagogia da Esperança, Pedagogia da Cidade, Pedagogia da Autonomia e Pedagogia da Indignação ${ }^{3}$. De Paulo Freire provém a noção de aprendizagem significativa, por exemplo.

Para outros educadores, a Educação Permanente em Saúde configura um desdobramento do Movimento Institucionalista em Educação, caracterizada fundamentalmente pela produção de René Lourau e George Lapassade (Lourau, 1975; Lapassade, 1983 ou Lourau \& Lapassade, 1972), que propuseram alterar a noção de Recursos Humanos, proveniente da Administração e depois da Psicologia Organizacional, como o elemento humano nas organizações, para a noção de coletivos de produção, propondo a criação de dispositivos para que o coletivo se reúna e discuta, reconhecendo que a educação se compõe necessariamente com a reformulação da estrutura e do processo produtivo em si nas formas singulares de cada tempo e lugar. Dos institucionalistas provém a noção de auto-análise e autogestão, por exemplo.

A Educação Permanente em Saúde configura, ainda, para outros educadores, o desdobramento, sem filiação, de vários movimentos de mudança na formação dos profissionais de saúde, resultando da análise das construções pedagógicas na educação em serviços de saúde, na educação continuada para o campo da saúde e na educação formal de profissionais de saúde. No caso brasileiro, em particular, verificamos, nos movimentos de mudança na atenção em saúde, a mais ampla intimidade cultural e analítica com Paulo Freire ${ }^{4}$; nos movimentos de mudança na gestão setorial, uma forte ligação e uma forte autonomia intelectual com origem ou passagem pelo movimento institucionalista ${ }^{5}$ e nos movimentos de mudança na educação de profissionais de saúde um intenso engajamento ${ }^{6}$, também com uma intensa produção original ${ }^{7}$. É deste reconhecimento nacional que tenho tangenciado, desde 2001 (Ceccim \& Armani, 2001), a noção de Quadrilátero da Formação, organizada mais recentemente no trabalho intelectual, político e institucional com Laura Feuerwerker (Ceccim \& Feuerwerker, 2004a).

Para fins deste debate, destaco que aquilo que deve ser realmente central à Educação Permanente em Saúde é sua porosidade à realidade mutável e mutante das ações e dos serviços de saúde; é sua ligação política com a formação de perfis profissionais e de serviços, a introdução de mecanismos, espaços e temas que geram auto-análise, autogestão, implicação, mudança institucional, enfim, pensamento (disruptura com instituídos, fórmulas ou modelos) e experimentação (em contexto, em afetividade - sendo afetado pela realidade/afecção).
${ }^{3}$ A obra de Paulo Freire em Educação se estende de 1959 a 2000. Para identificar o período do primeiro bloco referido, pode-se indicar Educação como prática da liberdade, obra original de 1967 (Freire, 1989) e, para o segundo bloco, Pedagoy of the city, de 1993 (Freire, 1995)

${ }^{4}$ Pode-se citar Victor Valla, Eduardo Stotz (Valla \& Stotz, 1993; 1994), Eymard Vasconcellos (Vasconcellos, 2001) e Sonia Acioli (Acioli, 2000) por exemplo.

${ }^{5}$ Pode-se citar Gastão Campos (Campos, 2003) Emerson Merhy (Merhy,

2002), Luiz Cecílio

(Cecílio, 1994) e Solange

L'Abbate (L'Abbate,

1997), por exemplo.

${ }^{6}$ Pode-se referir a rede de integração docenteassistencial, os projetos UNI e a rede Unida, pode-se citar Roseni Sena (Sena-Chompré, 1998), Laura Feuerwerker (Feuerwerker, 2002), Regina Marsiglia

(Marsiglia, 1995; 1998) e Márcio Almeida (Almeida, 1999), por exemplo.

${ }^{7}$ Pode-se referir a Comissão Nacional Interinstitucional de Avaliação do Ensino Médico (Cinaem), pode-se citar Regina Stella (Stella 2001), Rogério Carvalho dos Santos, Roberto

Piccini e Luiz Augusto Facchini (Santos et al., 2000) ou, ainda, Emerson Merhy (Merhy, 2002), por exemplo. 


\section{Exercício da Educação Permanente em Saúde}

Além da velocidade com que conhecimentos e saberes tecnológicos se renovam na área da saúde, a distribuição de profissionais e de serviços segundo o princípio da acessibilidade para o conjunto da população o mais próximo de sua moradia - ou de onde procuram por atendimento - faz com que se torne muito complexa a atualização permanente dos trabalhadores. Torna-se crucial o desenvolvimento de recursos tecnológicos de operação do trabalho perfilados pela noção de aprender a aprender, de trabalhar em equipe, de construir cotidianos eles mesmos como objeto de aprendizagem individual, coletiva e institucional.

Não há saída, como não há romantismo nisso. Problemas como a baixa disponibilidade de profissionais, a distribuição irregular com grande concentração em centros urbanos e regiões mais desenvolvidas, a crescente especialização e suas conseqüências sobre os custos econômicos e dependência de tecnologias mais sofisticadas, o predomínio da formação hospitalar e centrada nos aspectos biológicos e tecnológicos da assistência demandam ambiciosas iniciativas de transformação da formação de trabalhadores.

Assim, ou constituímos equipes multiprofissionais, coletivos de trabalho, lógicas apoiadoras e de fortalecimento e consistência de práticas uns dos outros nessa equipe, orientadas pela sempre maior resolutividade dos problemas de saúde das populações locais ou referidas ou colocamos em risco a qualidade de nosso trabalho, porque sempre seremos poucos, sempre estaremos desatualizados, nunca dominaremos tudo o que se requer em situações complexas de necessidades em/direitos à saúde.

A complexidade fica ainda maior em situações concretas, nas quais a presença de saberes tradicionais das culturas ou a produção de sentidos ligada ao processo saúdedoença-cuidado-qualidade de vida pertence a lógicas distintas do modelo racional científico vigente entre os profissionais de saúde, pois não será sem a mais justa e adequada composição de saberes que se alcançará uma clínica que fale da vida real, uma clínica com capacidade terapêutica.

Um dos entraves à concretização das metas de saúde tem sido a compreensão da gestão da formação como atividade meio, secundária à formulação de políticas de atenção à saúde. Nem é dirigida às políticas de gestão setorial ou das ações e dos serviços de saúde e nem é compreendida como atividade finalística da política setorial.

Tradicionalmente, falamos da formação como se os trabalhadores pudessem ser administrados como um dos componentes de um espectro de recursos, como os materiais, financeiros, infraestruturais etc. e como se fosse possível apenas "prescrever" habilidades, comportamentos e perfis aos trabalhadores do setor para que as ações e os serviços sejam implementados com a qualidade desejada. As prescrições de trabalho, entretanto, não se traduzem em trabalho realizado/sob realização.

As reformas setoriais em saúde têm-se deparado regularmente com a necessidade de organizar ofertas políticas específicas ao segmento dos trabalhadores, a tal ponto que esse componente (o "Recursos Humanos") chegou a configurar uma área específica de estudos nas políticas públicas de saúde. Parece-nos impostergável assegurar à área da formação, então, não mais um lugar secundário ou de retaguarda, mas um lugar central, finalístico, às políticas de saúde. A introdução desta abordagem retiraria os trabalhadores da condição de "recursos" para o estatuto de atores sociais das reformas, do trabalho, das lutas pelo direito à saúde e do ordenamento de práticas acolhedoras e resolutivas de gestão e de atenção à saúde.

A introdução da Educação Permanente em Saúde seria estratégia fundamental para a 
recomposição das práticas de formação, atenção, gestão, formulação de políticas e controle social no setor da saúde, estabelecendo ações intersetoriais oficiais e regulares com o setor da educação, submetendo os processos de mudança na graduação, nas residências, na pós-graduação e na educação técnica à ampla permeabilidade das necessidades/direitos de saúde da população e da universalização e eqüidade das ações e dos serviços de saúde.

Uma ação organizada na direção de uma política da formação pode marcar estas concepções na gestão do sistema de saúde, mas também demarca uma relação com a população, entendida como cidadãos de direitos. Tal iniciativa pode fazer com que os cidadãos reconheçam tanto a preocupação com a macropolítica de proteção à saúde, como com o desenvolvimento de práticas para a organização do cotidiano de cuidados às pessoas, registrando uma política da valorização do trabalho e do acolhimento oferecido aos usuários das ações e dos serviços de saúde, tendo em vista a construção da acessibilidade e resolutividade da atenção e do sistema de saúde como um todo e o desenvolvimento da autonomia dos usuários diante do cuidado e da capacidade de gestão social das políticas públicas de saúde.

\section{Formação para a Educação Permanente em Saúde}

Tradicionalmente, o setor da saúde trabalha com a política de modo fragmentado: saúde coletiva separada da clínica, qualidade da clínica independente da qualidade da gestão, gestão separada da atenção, atenção separada da vigilância, vigilância separada da proteção aos agravos externos e cada um desses fragmentos divididos em tantas áreas técnicas quantos sejam os campos de saber especializado. Essa fragmentação também tem gerado especialistas, intelectuais e consultores (expertises) com uma noção de concentração de saberes que terminam por se impor sobre os profissionais, os serviços e a sociedade e cujo resultado é a expropriação dos demais saberes e a anulação das realidades locais em nome do conhecimento/da expertise.

Cada área técnica sempre parte do máximo de conhecimentos acumulados em seu núcleo de saberes e de práticas e dos princípios políticos considerados mais avançados, segundo a erudição oriunda deste núcleo de informações, para examinar os problemas de saúde do país. A partir dessas referências propõem "políticas específicas" ou, como tradicionalmente acontece, "programas de ação" ou "ações programáticas", quase sempre assentadas na assistência individual, em particular sobre o atendimento médico, ou em macropolíticas de vigilância à saúde. Para a implementação de cada "programa de ação", propõe-se uma linha de capacitações, isto é, uma linha de prescrições de trabalho aos profissionais. Essa linha de capacitações/prescrições substitui o papel das áreas técnicas e dos níveis centrais em definir princípios e diretrizes para as políticas em cada um dos núcleos específicos de acumulação em saúde e, a partir daí, em lugar de estabelecer apoio solidário às esferas gestoras ou de serviços nas quais se desdobram em atos políticos, desfiam cursos, treinamentos e protocolos. As áreas técnicas, tradicionalmente, sem nenhum pudor, se oferecem à prescrição do trabalho e negam sua oportunidade de assessoramento.

Em geral, as áreas, os intelectuais especialistas e os consultores trabalham com dados gerais que possibilitam identificar a existência dos problemas e sugerir sua explicação, mas não permitem compreender sua singularidade, sua vigência subjetiva, suas conexões de sentido local. O olhar, a escuta e o assessoramento que permitem compreender a especificidade da gênese de cada problema é necessariamente afetiva e 
local, portanto, é imprescindível que haja encontro entre intelectuais e consultorias docentes com a gestão de sistemas e serviços locais para a elaboração de estratégias adequadas ao enfrentamento efetivo dos problemas. Todos e cada um dos que trabalham nos serviços de saúde, na atenção e na gestão dos sistemas e serviços têm idéias, noções e compreensão acerca da saúde e de sua produção, do sistema de saúde e de sua operação e do papel que cada profissional ou cada unidade setorial deve cumprir na prestação das ações de saúde. É a partir dessas idéias, noções e compreensão que cada profissional se integra às equipes ou agrupamentos de profissionais em cada ponto do sistema. É a partir dessas concepções, mediadas pela organização dos serviços e do sistema, que cada profissional opera.

Ao analisarmos um problema institucional, regional ou nacional de maneira contextualizada, descobrimos a complexidade de sua explicação e a necessidade de intervenções articuladas. As capacitações não se mostram eficazes para possibilitar a incorporação de novos conceitos e princípios às práticas estabelecidas - tanto de gestão, como de atenção e de controle social - por trabalharem de maneira descontextualizada e se basearem principalmente na transmissão de conhecimentos. A Educação Permanente em Saúde pode ser orientadora das iniciativas de desenvolvimento dos profissionais e das estratégias de transformação das práticas de saúde.

Condição indispensável para uma pessoa ou uma organização decidir mudar ou incorporar novos elementos a sua prática e a seus conceitos é a detecção e contato com os desconfortos experimentados no cotidiano do trabalho, a percepção de que a maneira vigente de fazer ou de pensar é insuficiente ou insatisfatória para dar conta dos desafios do trabalho. Esse desconforto ou percepção de abertura (incerteza) tem de ser intensamente admitido, vivido, percebido. Não se contata o desconforto mediante aproximações discursivas externas. A vivência e/ou a reflexão sobre as práticas vividas é que podem produzir o contato com o desconforto e, depois, a disposição para produzir alternativas de práticas e de conceitos, para enfrentar o desafio de produzir transformações.

Para produzir mudanças de práticas de gestão e de atenção, é fundamental que sejamos capazes de dialogar com as práticas e concepções vigentes, que sejamos capazes de problematizá-las - não em abstrato, mas no concreto do trabalho de cada equipe - e de construir novos pactos de convivência e práticas, que aproximem os serviços de saúde dos conceitos da atenção integral, humanizada e de qualidade, da eqüidade e dos demais marcos dos processos de reforma do sistema brasileiro de saúde, pelo menos no nosso caso.

Cresce a importância de que as práticas educativas configurem dispositivos para a análise da(s) experiência(s) locais; da organização de ações em rede/em cadeia; das possibilidades de integração entre formação, desenvolvimento docente, mudanças na gestão e nas práticas de atenção à saúde, fortalecimento da participação popular e valorização dos saberes locais.

As consultorias, os apoios, as assessorias quando implementadas têm de ser capazes de organizar sua prática de modo que esta produção seja possível; elas precisam oferecer-se desde a pedagogia da Educação Permanente em Saúde para que façam sentido na realidade e operem processos significativos nessa realidade.

Novas abordagens, mais potentes para desfazer as dicotomias persistentes e sobre as quais foram construídas as iniciativas anteriores de mudança (individual $x$ coletivo, clínica $x$ saúde pública, especialidade $x$ generalidade, sofisticação tecnológica $x$ abordagens simplificadas) tornam-se impostergáveis. 


\section{A Educação Permanente em Saúde opera o Quadrilátero da Formação}

A interação entre os segmentos da formação, da atenção, da gestão e do controle social em saúde deveria permitir dignificar as características locais, valorizar as capacidades instaladas, desenvolver as potencialidades existentes em cada realidade, estabelecer a aprendizagem significativa e a efetiva e criativa capacidade de crítica, bem como produzir sentidos, auto-análise e autogestão ${ }^{8}$. Para tanto, teremos de pensar/providenciar subsídios para que se pense/providencie a Educação Permanente em Saúde.

Dentre os elementos analisadores para pensar/providenciar a Educação Permanente em Saúde estão os componentes do Quadrilátero da Formação:

a) análise da educação dos profissionais de saúde: mudar a concepção hegemônica tradicional (biologicista, mecanicista, centrada no professor e na transmissão) para uma concepção construtivista (interacionista, de problematização das práticas e dos saberes); mudar a concepção lógico-racionalista, elitista e concentradora da produção de conhecimento (por centros de excelência e segundo uma produção tecnicista) para o incentivo à produção de conhecimento dos serviços e à produção de conhecimento por argumentos de sensibilidade;

b) análise das práticas de atenção à saúde: construir novas práticas de saúde, tendo em vista os desafios da integralidade e da humanização e da inclusão da participação dos usuários no planejamento terapêutico;

c) análise da gestão setorial: configurar de modo criativo e original a rede de serviços, assegurar redes de atenção às necessidades em saúde e considerar na avaliação a satisfação dos usuários;

d) análise da organização social: verificar a presença dos movimentos sociais, dar guarida à visão ampliada das lutas por saúde e à construção do atendimento às necessidades sociais por saúde.

O papel das práticas educativas deve ser crítica e incisivamente revisto para que almeje a possibilidade de pertencer aos serviços/profissionais/estudantes a que se dirigem, de forma que os conhecimentos que veiculam alcancem significativo cruzamento entre os saberes formais previstos pelos estudiosos ou especialistas e os saberes operadores das realidades - detidos pelos profissionais em atuação - para que viabilizem auto-análise e principalmente autogestão. Os saberes formais devem estar implicados com movimentos de auto-análise e autogestão dos coletivos da realidade, pois são os atores do cotidiano que devem ser protagonistas da mudança de realidade desejada pelas práticas educativas.

Uma questão à auto-análise e à autogestão dos coletivos é o trabalho com eixo na integralidade para superar a modelagem de serviços centrados em procedimentos, de usuários interpretados como peças orgânicas ou como o simples território onde evoluem os quadros fisiopatológicos e de doenças enfrentadas como eventos biológicos (como se esse conhecimento fosse de ciências naturais) $)^{9}$.

Dessa maneira, além de processos que permitam incorporar tecnologias e referenciais necessários, é preciso implementar espaços de discussão, análise e reflexão da prática no cotidiano do trabalho e dos referenciais que orientam essas práticas, com apoiadores matriciais de outras áreas, ativadores de processos de mudança institucional e facilitadores de coletivos organizados para a produção.

Tomar o cotidiano como lugar aberto à revisão permanente e gerar o desconforto com os lugares "como estão/como são", deixar o conforto com as cenas "como estavam/como eram" e abrir os serviços como lugares de produção de subjetividade, tomar as relações como produção, como lugar de problematização, como abertura para a produção e não
${ }^{8}$ Pode-se sugerir a leitura da produção em colaboração de Ceccim \& Feuerwerker, 2004a e b.
${ }^{9}$ Para compreender a integralidade, pode-se citar outros brasileiros: Ruben Mattos, Roseni Pinheiro (Pinheiro \& Mattos, 2001; 2003 ; 2004), Kenneth Camargo Jr. (Camargo Jr., 2003) e Madel Luz (Luz, 1988), por exemplo. 
como conformação permite praticar contundentemente a Educação Permanente em Saúde.

Para ocupar o lugar ativo da Educação Permanente em Saúde precisamos abandonar (desaprender) o sujeito que somos, por isso mais que sermos sujeitos (assujeitados pelos modelos hegemônicos e/ou pelos papéis instituídos) precisamos ser produção de subjetividade: todo o tempo abrindo fronteiras, desterritorializando grades (gradis) de comportamento ou de gestão do processo de trabalho. Precisamos, portanto, também trabalhar no deslocamento dos padrões de subjetividade hegemônicos: deixar de ser os sujeitos que vimos sendo, por exemplo, que se encaixam em modelos prévios de ser profissional, de ser estudante, de ser paciente (confortáveis nas cenas clássicas e duras da clínica tradicional, mecanicista, biologicista, procedimento-centrada e medicalizadora).

Se somos atores ativos das cenas de formação e trabalho (produtos e produtores das cenas, em ato), os eventos em cena nos produzem diferença, nos afetam, nos modificam, produzindo abalos em nosso "ser sujeito", colocando-nos em permanente produção. O permanente é o aqui-e-agora, diante de problemas reais, pessoas reais e equipes reais.

A mudança na formação por si só ajuda, mas essa mudança como política se instaura em mais lugares, todos os do Quadrilátero, pois todos esses lugares estão conformados em acoplamento de captura da Educação Permanente em Saúde. Tanto a incorporação crítica de tecnologias materiais, como a eficácia da clínica produzida, os padrões de escuta, as relações estabelecidas com os usuários e entre os profissionais representam a captura da Educação Permanente em Saúde e, por conseguinte, dos processos de mudança. É por isso que a Educação Permanente em Saúde é um desafio ambicioso e necessário.

\section{Referências}

ACIOLI, S. Novas práticas em saúde: estratégias e práticas de grupos populares no enfrentamento de questões cotidianas. Rio de Janeiro: IMS/UERJ, 2000. (Série Estudos em Saúde Coletiva).

ALMEIDA, M. J. Educação médica e saúde: possibilidades de mudança. Londrina: UEL; Rio de Janeiro: ABEM, 1999.

CAMARGO JR., K. Biomedicina, saber e ciência: uma abordagem crítica. São Paulo: Hucitec, 2003.

CAMPOS, G. W. S. (Org.) Saúde Paidéia. São Paulo: Hucitec, 2003.

CECCIM, R. B.; ARMANI, T. B. Educação na saúde coletiva. Divulg. Saúde Debate, n.23, p.30-56, dez. 2001.

CECCIM, R. B.; FEUERWERKER, L. O quadrilátero da formação para a área da saúde: ensino, gestão, atenção e controle social. Physis - Rev. Saúde Coletiva, v.14, n.1, p.41-65, 2004a.

CECCIM, R. B.; FEUERWERKER, L. Mudança na graduação das profissões de saúde sob o eixo da integralidade. Cad. Saúde Pública, v.20, n.5, p.1400-10, 2004b.

CECÍLIO, L .C. O. (Org.) Inventando a mudança na saúde. São Paulo: Hucitec, 1994.

FEUERWERKER, L. Além do discurso de mudança na educação médica: processos e resultados. São Paulo: Hucitec; Londrina: Rede Unida; Rio de Janeiro: Abem, 2002.

FREIRE, P. Educação como prática da liberdade. 19.ed. Rio de Janeiro: Paz e Terra, 1989.

FREIRE, P. Pedagogy of the city. New York: Continuum, 1995. 
L'ABBATE, S. Comunicação e educação: uma prática de saúde. In: MERHY, E. E.; ONOCKO, R. (Orgs.) Agir em saúde: um desafio para o público. São Paulo: Hucitec; Buenos Aires: Lugar Editorial, 1997. p.267-92.

LAPASSADE, G. Grupos, organizações e instituições. 2.ed. Rio de Janeiro: Francisco Alves, 1983.

LOURAU, R. A análise institucional. Petrópolis: Vozes, 1975.

LOURAU, R.; LAPASSADE, G. Chaves da Sociologia. Rio de Janeiro: Civilização Brasileira, 1972.

LUZ, M. Natural, racional, social: razão médica e racionalidade científica moderna. Rio de Janeiro: Campus, 1988.

MARSIGLIA, R. G. Relação ensino/serviços: dez anos de integração docente-assistencial no Brasil. São Paulo: Hucitec, 1995.

MARSIGLIA, R. G. Perspectivas para o ensino das ciências sociais na graduação odontológica. In: BOTAZZO, C.; FREITAS, S. F. T. (Orgs.) Ciências sociais e saúde bucal: questões e perspectivas. São Paulo: Unesp; Bauru: Edusc, 1998. p.175-96.

MERHY, E. E. Saúde: a cartografia do trabalho vivo. São Paulo: Hucitec, 2002.

PINHEIRO, R.; MATTOS, R. A. (Orgs.) Os sentidos da integralidade na atenção e no cuidado à saúde. Rio de Janeiro: Uerj/Abrasco, 2001.

PINHEIRO, R.; MATTOS, R. A. (Orgs.) Construção da integralidade: cotidiano, saberes e práticas em saúde. Rio de Janeiro: UERJ/Abrasco, 2003.

PINHEIRO, R.; MATTOS, R. A. (Orgs.) Cuidado: as fronteiras da integralidade. São Paulo: Hucitec; 2004.

ROSCHKE, M. A.; DAVINI, M. C.; HADDAD, J. (Eds.) Educación permanente de personal de salud. Washington: OPS, 1994. (Série Desarollo de Recursos Humanos, 100)

ROSCHKE, M. A.; BRITO, P. Gestión de proyectos de educación permanente en los servicios de salud: manual del educador. Washington: OPS, 2002.

ROVERE, M. Planificación estratégica de recursos humanos en salud. Washington: OPS, 1996. (Série Desarollo de Recursos Humanos, 96)

SANTOS, R. C.; PICCINI, R.; FACHHINI, L. A. (Org.) Comissão Interinstitucional Nacional de Avaliação do Ensino Médico: preparando a transformação da educação médica brasileira. Projeto Cinaem, III fase relatório 1999-2000. Pelotas: Cinaem: UFPel, 2000.

SENA-CHOMPRÉ, R. A enfermagem nos projetos UNI: contribuição para um novo projeto para a enfermagem brasileira. São Paulo: Hucitec, 1998.

STELLA, R. C. R. Conquistas e desafios. Editorial. Rev. Bras. Educ. Méd., p.5-6, v.25, n.3, 2001.

VALLA, V.; STOTZ, E. Participação popular, educação e saúde: teoria e prática. 2.ed. Rio de Janeiro: Relume-Dumará, 1993.

VALLA, V.; STOTZ, E. Educação, saúde e cidadania. Petrópolis: Vozes, 1994.

VASCONCELLOS, E. M. (Org.) A saúde nas palavras e nos gestos: reflexões da rede de educação popular e saúde. São Paulo: Hucitec, 2001.

Recebido para publicação em 18/10/04 Aprovado para publicação em 27/10/04 